\title{
Lethal midline granuloma
}

\section{Pirabu Sakthivel ${ }^{1 *}$ and Madhu Rajeshwari ${ }^{2}$}

${ }^{1}$ Department of Otorhinolaryngology \& Head and Neck surgery, All India Institute of Medical Sciences, New Delhi, India ${ }^{2}$ Department of Pathology, All India Institute of Medical Sciences, New Delhi, India

A 36-year-old man presented with crusted lesions on his forehead, dorsum of nose and right eye that had developed over a period of 2 months. He had occasional bloody and purulent discharge, without pain, and did not have constitutional or other systemic symptoms. Ocular examination revealed bilateral peri-orbital edema with erythema, conjunctival chemosis with right upper eyelid completely replaced by crusts, exposing the cornea (Figure 1A) resulting in absent vision on the right side. A clinical diagnosis of lethal midlinegranuloma was considered. Hematological investigations revealed leucocytosis with relative lymphocytosis and raised ESR. Urine microscopy (for casts or hematuria) and sputum analysis were normal. Biochemical tests for c-ANCA, p-ANCA and HIV were negative. Chest X-ray was
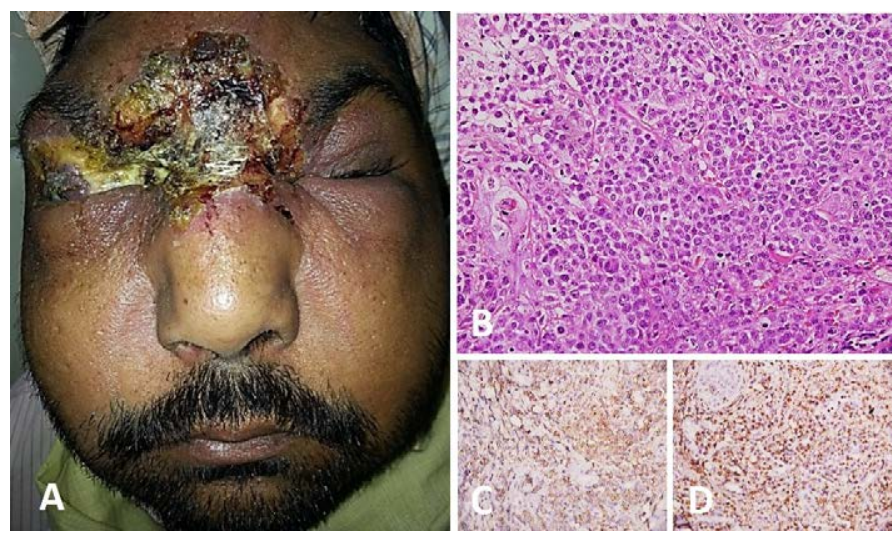

Figure 1A. Clinical image showing crusted lesion over forehead, root of nose and right eye with necrotic slough and blood crusts and exposed cornea on the right side, Figure 1B-1D. Photomicrograph showing an infiltrate comprising of intermediate sized atypical lymphoid cells (B, H\&E x400) expressing NK- T cell markers CD56 (C) and Granzyme (D). normal. Computed tomography revealed soft tissue thickening and bony involvement with no lymphadenopathy or metastases.Multiple skin biopsies eventually confirmed NK/T cell lymphoma (Figures 1B-1D).The patient was admitted and SMILE regimen chemotherapy was started. However, the patient developed immunosuppression and meningitis with disease progression leading to death during hospital stay.

\section{Consent}

Informed written consent was obtained from the patient's father.

\section{Conflicts of interest}

Nil
Copyright: (C)2017 Sakthivel P. This is an open-access article distributed under the terms of the Creative Commons Attribution License, which permits unrestricted use, distribution, and reproduction in any medium, provided the original author and source are credited.
Correspondence to: Pirabu Sakthivel, M.S., DNB, ENT,Department of Otorhinolaryngology and Head \& Neck surgery,All India Institute of Medical Sciences, New Delhi - 110029, India, Tel: 9958744547; E- mail: pirabusakthivel@gmail. com

Received: July 10, 2017; Accepted: July 13, 2017; Published: July 18, 2017 